\title{
FAO AquaCrop Modeli Kullanılarak Farklı Sulama Programı Koşullarında Patates Bitkisinde Verim Tahmini
}

\author{
Derya Beyhan Yiğit ${ }^{1 *} \quad$ Burak Nazmi Candoğan ${ }^{2}$
}

${ }^{1}$ Devlet Su İşleri 1. Bölge Müdürlüğü, Bursa

${ }^{2}$ Uludağ Üniversitesi, Ziraat Fakültesi, Biyosistem Mühendisliği Bölümü, Bursa

*Sorumlu yazar: derya.byhn@gmail.com, deryabeyhan@dsi.gov.tr

\section{$\ddot{O} z$}

AquaCrop, 2009 yılında Birleşmiş Milletler Gıda ve Tarım Örgütü (FAO) tarafından geliştirilmiş farklı sulama stratejileri ve doğal koşullarda bitki gelişimini ve gelişim sonunda elde edilebilecek verimi tahmin eden bir simülasyon modelidir. AquaCrop'un geliştirilme felsefesi su odaklıdır. Model, bitki su tüketimi ve verimin tahmin edilmesinde, atmosfer, bitki, toprak ve yönetim (sulama, gübreleme vb.) bileşenlerini girdi olarak kullanmaktadır. Bitki su tüketiminin tahmin edilmesinde, bitki terlemesi ve topraktan buharlaşmayı ayırmakta ve bitki gelişiminin simüle edilmesinde yaprak alan indeksi yerine örtü yüzdesi parametresini kullanarak sonuca ulaşmaktadır.

Bu çalışmada, AquaCrop modeli kullanılarak Güney Marmara Bölgesinde geniş çaplı yetiştiriciliği yapılan Hermes patates çeşidi için damla sulama yöntemi altında iki farklı sulama programı oluşturulmuş ve kuru verim tahmin edilmiştir. Birinci sulama programı (S1), toprak su içeriğinin patates bitkisi için stomaların kapanmaya başladığı toprak suyu tüketim seviyesine düştüğünde, tarla kapasitesine tamamlayacak miktarda sulama suyu uygulanması şeklinde modele tanımlanmıştır. İkinci sulama programı (S2) toprak su içeriğinin S1 sulama programında belirtilen kritik düzeyin yarısına düşünce tarla kapasitesine tamamlayacak miktarda sulama suyu uygulanması şeklinde oluşturulmuştur. Sonuç olarak, S1 ve S2 sulama programları için sırasılyla 9.685 tha ${ }^{-}$ ${ }^{1}$ ve $9.535 \mathrm{t} \mathrm{ha}^{-1}$ olmak üzere birbirine yakın kuru verim değerleri tahmin edilmiş ve suyun tasarruflu kullanımı bakımından S1 sulama programı öne çıkmıştır.

Anahtar Kelimeler: Verim tahmini, Sulama, Patates, FAO AquaCrop

\section{Estimation of Potato Yield Using FAO AquaCrop Model Under Different Irrigation Schedules}

\section{Abstract}

AquaCrop simulates attainable yields of major herbaceous crops as a function of water consumption under different irrigation strategies and natural conditions that was developed by United Nations Food and Agriculture Organization (FAO) in 2009. The growth engine of AquaCrop is water-driven. Input consists of weather data, crop and soil characteristics, and management practices (irrigation, fertilization etc.) that define the environment in which the crop will develop. The model separate evapotranspiration which into soil evaporation and crop transpiration avoids the confounding effect of the non-productive consumptive use of water (soil evaporation) and instead of leaf area index AquaCrop uses green canopy cover to express foliage development.

In this study, two different irrigation schedules were created under the drip irrigation method for the Hermes potato variety grown in the Southern Marmara Region using the AquaCrop model and the dry yield was estimated. The first irrigation schedule (S1) is described as the application of irrigation water to the field capacity, when the soil water content falls below the soil water depletion level at which the stomata closure begin for the potato plant. The second (S2) is defined as the application of irrigation water that will meet the field capacity to half of the critical level specified in the S1 irrigation schedule. As a result, close dry yield values of $9685 \mathrm{t} \mathrm{ha}^{-1}$ and $9535 \mathrm{t} \mathrm{h}^{-1}$ were estimated for S1 and S2 irrigation schedule, respectively. S1 irrigation schedule came to the fore in terms of water saving use.

Key words: Yield estimation, Irrigation, Potato, FAO AquaCrop

\section{Giriş}

Patates üretimi, Türkiye'de 1970 yılı ve sonrasında ivme kazanmış ve üretimin \%80’i Bursa'nın da aralarında bulunduğu 14 ilde gerçekleşmektedir (Arığlu ve ark., 2006). Ülkemizde 
patates üretimi yapılan tarım alanı azalırken, verim artmış ve 2006 yılında 4.366 .000 ton olan toplam patates üretimi, 2015 yllında 4.760 .000 ton' a ulaşmıştır. Patates üretiminin talep doğrultusundaki yeterlilik derecesi ise \%100'e yakınlık göstermektedir. Patates tohumu üretim miktarı ise 2002 yılında 21.375 ton civarında iken 2015 yılında sekiz kat artış göstererek 175.397 ton' a ulaşmıştır (GTHBBUGEM, 2016).

Patates bitkisinde sulama çalışmaları üzerine literatür incelendiğinde; Doorenbos ve Kassam (1979) patates bitkisinde sulama sezonu boyunca toprağın kullanılabilir su tutma kapasitesinin (TAW) $\% 50$ 'den fazla tüketilmesi durumunda verimde kayıpların yaşanabileceği ve patatesin su tüketiminin $\left(E T_{c}\right)$ koşullara bağlı olarak 500-700 mm arasında değişebileceğini belirtmişlerdir. Konya Ovası'nda yürütülen patates bitkisinde sulama yöntemlerinin karşılaştırıldığı çalışmada, 3 farklı sulama yöntemi (damla, yağmurlama ve karık sulama) altında yetiştiricilik yapılmış, en az $\mathrm{ET}_{\mathrm{c}}$ değeri damla sulama yöntemi için ortalama $572 \mathrm{~mm}$ olarak bulunmuştur (Yavuz, 2011). Bursa İli Yenişehir İlçesinde yetiştiriciliği yapılan Hermes patates çeşidinde, damla sulama yöntemi ile uygulanan kısıntılı sulamanın verime etkisinin belirlenmesi amacıyla iki yıl süreyle yürütülen çalışma sonucunda, kısıntılı sulamanın bitki verimi üzerinde önemli etkileri gözlenmiştir (Ayas, 2007). Hindistan'da yürütülen diğer bir çalışmada, TAW'ın \%60 ve \%75'i tüketildiğinde eksilen suyun tarla kapasitesine ulaştırıldığ deneme konularında patates veriminde önemli azalmalar meydana gelmiştir (Kashyap ve Panda, 2003).

Diğer taraftan arazi çalışmaları yanında, bilgisayar teknolojisinin gelişmesiyle, bitki gelişim süreçlerini simüle eden (tasvir eden) bilgisayar programları giderek önem kazanmıştır. Bitki gelişimi simülasyon modelleri olarak tanımlanan bu programlar sulama zamanının belirlenmesinde ve bitki gelişim süreçlerinin izlenebilmesinde kullanılmaktadır. Atmosfer-bitki-toprak-su ilişkisini daha iyi analiz etmek için kullanılan bitki gelişim simülasyon modelleri ile toprak, bitki ve iklim bileşenlerinin bitki gelişimine ve verime olan etkilerini belirlemek mümkün olmaktadır (Yazgan ve Tatar, 2003). Bu amaçla, Birleşmiş Milletler Gıda ve Tarım Örgütü (FAO), 2009 yılında, AquaCrop adında tam, kısıntılı, destekleyici sulama koşulları ve yağışa dayalı koşullarda bitki gelişimini ve elde edilebilecek verimi tahmin eden bir simülasyon modeli geliştirmiştir (Steduto ve ark., 2009). Model $\mathrm{ET}_{\mathrm{c}}$ 'den yola çıkarak, elde edilmesi beklenen verimi tahmin edebilen ve bitki gelişimini görsel olarak simüle edebilen bir bitki gelişim benzeşim modelidir. AquaCrop, mısır (Hsiao ve ark., 2009), pamuk (GarcíaVila ve ark., 2009), ayçiçeği (Todorovic ve ark., 2009), kinoa (Geerts ve ark., 2009), arpa (Araya ve ark., 2010), kolza (Zeleke ve ark., 2011) ve kışlık buğday (Kale ve Tarı, 2012) bitkileri için test edilmiş ve verim doğru olarak tahmin edilebilmiştir. Bununla birlikte, AquaCrop modelinin farklı iklim, toprak ve bitki koşullarında alternatif sulama programları altında test edilerek uygunluğunun belirlenmesi önemlidir.

Bu çalışmada temel olarak, Marmara Bölgesi’nin güney-doğusunda yer alan yarı-nemli iklim koşullarının hüküm sürdüğü, Türkiye patates üretiminde büyük bir paya sahip Bursa İli (Ayas, 2007) baz alınarak, AquaCrop 5.0 modeli ile farklı sulama programlarının oluşturulması, patates bitkisi verim tahminlerinin yapılması ve sonuçların değerlendirilmesi amaçlanmıştır.

\section{Materyal ve Yöntem}

\section{AquaCrop Modeli}

$\mathrm{Bu}$ çalışmada, damla sulama yöntemi ve farklı sulama programı koşullarında patates $\mathrm{ET}_{\mathrm{c}}$ değerleri, sulama suyu ihtiyacı ve verim tahmini için FAO resmi internet sitesinden edinilen AquaCrop 5.0 modeli (FAO, 2015) kullanılmıştır. AquaCrop 5.0 modelinin bilimsel temeli Steduto ve ark. (2009), Raes ve ark. (2009) ve Hsiao ark. (2009) tarafindan açıklanmıştır.

AquaCrop, suya verim tepkisini kestirmek için diğer simülasyon modellerine göre nispeten daha az sayıda parametre ve girdi verisine gereksinim duyan su odaklı çalışan bir modeldir. Bitkinin yetiştirileceği çevreyi tanımlamada yardımcı iklim verileri, toprak ve bitki özellikleri ile bitki yönetim uygulamaları girdi verilerini oluşturmaktadır. Girdiler; iklim, bitki, toprak ve yönetim dosyalarında saklanmakta ve kolayca kullanıcı tarafından değiştirilebilmektedir (Raes ve ark., 2011).

\section{İklim Verileri}

Bursa İli Meteoroloji Genel Müdürlüğü (MGM)'ne ait merkez meteoroloji istasyonu uzun y1llar aylık ortalama meteorolojik verileri Çizelge 1'de verilmiştir (MGM, 2013). Yıllık toplam yağış miktarı $(698.1 \mathrm{~mm})$ dikkate alındığında, bölgede yarı-nemli iklim koşulları hüküm sürmektedir 
(Jensen, 1980). Ayrıca Bursa İli Aydeniz, Erinç ve Thornthwaite iklim sınıflandırmalarına göre yarı nemli, DeMartonne iklim sınıflandırmasına göre de yarı kurak-nemli arası bir iklime sahiptir (MGM, 2018).

Çizelge 1. Çalışma alanına ilişkin uzun yıllar aylık ortalama iklim verileri (1970-2012)

\begin{tabular}{lcccccc}
\hline Aylar & $\begin{array}{c}\text { En düşük } \\
\text { sıcaklık } \\
\left({ }^{\circ} \mathbf{C}\right)\end{array}$ & $\begin{array}{c}\text { En yüksek } \\
\text { sicaklık } \\
\left({ }^{\circ} \mathbf{C}\right)\end{array}$ & $\begin{array}{c}\text { Nispi nem } \\
\mathbf{( \% )}\end{array}$ & $\begin{array}{c}\text { Ortalama } \\
\text { rüzgar hızı } \\
\left(\mathbf{m ~ s}^{-1}\right)\end{array}$ & $\begin{array}{c}\text { Günlük toplam } \\
\text { güneşlenme } \\
\text { süresi (saat) }\end{array}$ & Yağış (mm) \\
\hline Ocak & 1,6 & 9,6 & 72 & 2,3 & 4,0 & 80,3 \\
Şubat & 2,0 & 10,7 & 71 & 2,4 & 3,2 & 72,2 \\
Mart & 3,6 & 13,8 & 70 & 2,3 & 4,1 & 67,4 \\
Nisan & 7,3 & 18,8 & 68 & 2,1 & 5,5 & 66,7 \\
Mayis & 11,2 & 23,7 & 66 & 2,0 & 7,8 & 45,1 \\
Haziran & 15,1 & 28,5 & 59 & 2,0 & 9,9 & 33,4 \\
Temmuz & 17,5 & 30,8 & 58 & 2,2 & 10,6 & 17,1 \\
Ağustos & 17,3 & 30,7 & 60 & 2,1 & 9,7 & 16,5 \\
Eylül & 13,7 & 27,1 & 66 & 1,8 & 7,7 & 40,4 \\
Ekim & 10,1 & 21,6 & 72 & 1,6 & 5,3 & 75,2 \\
Kasim & 5,6 & 15,9 & 73 & 1,7 & 5,0 & 80,6 \\
Aralık & 3,3 & 11,3 & 73 & 2,2 & 2,9 & 103,2 \\
\hline Ort./Top. & 9,0 & 20,2 & 67 & 2,1 & 6,3 & 698,1 \\
\hline
\end{tabular}

AquaCrop'un iklim bileşeni ve girdi olarak kullanılan diğer meteorolojik değişkenler $\left(\mathrm{CO}_{2}\right.$ konsantrasyonu vb.) modelin iklimsel verilerini oluşturmaktadır (Steduto ve ark., 2009). AquaCrop'u çalıştırmak için; referans bitki su tüketimi (ETo), en düşük ve en yüksek hava sıcaklıkları, yağış ve atmosferdeki yıllık ortalama $\mathrm{CO}_{2}$ konsantrasyonu olmak üzere 4 atmosferik girdi kullanılmaktadır. $\mathrm{CO}_{2}$ konsantrasyonu Hawaii Maura Loa Rasathanesi kayıtlarından elde edilmektedir (Raes ve ark., 2011). AquaCrop 5.0, referans bitki su tüketimi (ETo) hesaplamasını içermemektedir. Çalışmada, FAO'nun resmi internet sitesinden sağlanan ETo hesaplayıcı ile uzun yıllar aylık ortalama en düşük sıcaklık, en yüksek sıcaklık, nispi nem, ortalama rüzgar hızı ve günlük güneşlenme süresi iklim verilerinden yararlanarak her bir ay için günlük ortalama ETo değerleri hesaplanmıştır (Raes, 2012).

\section{Bitki Verileri}

Modelde, Güney Marmara'da ve Bursa İli ve ilçelerinde yetiştiriciliği yapılan patates bitkisi (Solanum tuberosum L.) özellikleri kullanılmıştır. Bu özellikler Çizelge 2'de verilmiştir (Stern ve Donald, 1963, Ayas, 2007; Mazurczyk ve ark., 2009). Yapılan literatür araştırması sonucu patates için en uygun yaprak alan indeksi (LAI) değeri 3,5 (Harper, 1963) olarak belirlenmiş ve bu değer kullanılarak en yüksek örtü yüzdesi değeri $\left(\mathrm{CC}_{\mathrm{x}}\right) \% 91$ olarak bulunmuştur (Ritchie 1972; Belmans ve ark., 1983; Ritchie ve ark., 1985; Farahani ve ark., 2009). Referans hasat indeksi $\left(\mathrm{HI}_{\mathrm{o}}\right)$ oran 1 ise \%75 (Mazurczyk ve ark., 2009) olarak dikkate alınmıştır.

Çizelge 2. Patates bitkisine ait özellikler

\begin{tabular}{ll} 
Bitkinin ekim zamanı $^{1}$ & 13 Nisan \\
Bitki yoğunluğu $^{1}$ & $71429 \mathrm{bitki} \mathrm{ha}^{-1}$ \\
Bitki filizlenme zamanı $^{1}$ & 20 gün \\
En geniş durumunda CC yüzdesi $^{1}$ & $\% 91$ \\
Bitki örtü yaşlanması dönemine ulaşma zamanı $^{1}$ & 60 . gün \\
Bitkinin olgunluğa ulaşma zamanı $^{1}$ & 132 . gün \\
Bitkinin çiçeklenme zamanı $^{1}$ & 72 gün \\
Etkili kök derinliği $^{1}$ & $60 \mathrm{~cm}$ \\
Referans HI yüzdesi $^{2}$ & $\% 75$ \\
\hline
\end{tabular}

${ }^{\mathrm{I}}$ Değişken parametre, ${ }^{2}$ Sabit parametre

\section{Toprak Verileri}

Çalışmada patates bitkisi için sulama programı oluşturulacak ve verim tahmini yapılacak toprakların, orta bünye sınıfında olduğu varsayılmış ve modelde $0-120 \mathrm{~cm}$ toprak derinliği için, 30 cm'lik toprak katmanları dikkate alınmıştır. Seçilen toprak bünyeleri için model tarafından varsayılmış 
toprak fiziksel özellikleri Çizelge 3'de verilmiştir. Toprak profilindeki infiltrasyonun ve derine sızmanın model tarafından tanımlanabilmesi için doymuş hidrolik iletkenlik (Ksat) ve toprağın drenaj katsayısı $(\tau)$ olarak modelde var olan değerler dikkate alınmıştır.

Çizelge 3. Seçilen toprak bünyeleri için model tarafından varsayılmış toprak fiziksel özellikleri

\begin{tabular}{|c|c|c|c|c|c|c|c|}
\hline $\begin{array}{l}\text { Toprak } \\
\text { Derinliği } \\
\text { (cm) }\end{array}$ & Bünye & $\begin{array}{l}\text { Tarla } \\
\text { kapasitesi }{ }^{1} \\
(\%)\end{array}$ & $\begin{array}{l}\text { Solma } \\
\text { noktasi }^{1} \\
(\%)\end{array}$ & $\begin{array}{l}\text { SAT }^{2} \\
(\%)\end{array}$ & $\begin{array}{l}\text { TAW } \\
\left(\mathrm{mm} \mathrm{m}^{-1}\right)\end{array}$ & $\begin{array}{l}\text { Ksat }^{3} \\
\left(\mathbf{m m}_{\text {gün }}{ }^{-1}\right)\end{array}$ & $\tau(\text { Tau })^{4}$ \\
\hline $0-30$ & Tin & 31,0 & 15,0 & 46,0 & 160 & 500,0 & 0,76 \\
\hline $30-60$ & Siltli Tın & 33,0 & 13,0 & 46,0 & 200 & 575,0 & 0,80 \\
\hline $60-90$ & Siltli Tın & 33,0 & 13,0 & 46,0 & 200 & 575,0 & 0,80 \\
\hline $90-120$ & Tin & 31,0 & 15,0 & 46,0 & 160 & 500,0 & 0,76 \\
\hline
\end{tabular}

${ }^{1}$ Hacim yüzdesi cinsinden, ${ }^{2}$ Doygun toprakta hacim yüzdesi cinsinde su içeriği, ${ }^{3}$ Doygun toprakta hidrolik iletkenlik, ${ }^{4}$ Drenaj katsayıs1

Kök bölgesindeki toprak su içeriğini (Wr) ve buna bağlı toprak su stresini takip etmek için AquaCrop her bir zaman adımında toprak su dengesini güncellemektedir. Toprak su dengesi çalışmalarında kök bölgesi genellikle bir rezervuar (hazne) olarak düşünülmektedir. Wr değişimi giren ve çıkan su akılarını takip ederek izlenmektedir. Yağış (P) ve sulama (I) ile toprağa su eklenmektedir. P'nin bir kısmı yüzey akıştan dolayı kaybedilebilmektedir. Su ayrıca, sı̆̆ bir yeraltı su tablasından k1lcal yükselme (CR) ile kök bölgesine ulaşabilmektedir. Topraktan buharlaşma (E), bitkiden terleme (Tr) ve derine sızma kayıpları (DP) gibi işlemler, toprak rezervuarından suyu uzaklaştırmaktadır. Böylece model tarafından kullanılan toprak su dengesi hesabı aşağıdaki eşitlikle ifade edilmiştir (Raes, 2017).

$W r_{t+1}=W r_{t}+(P-R O)+I+C R-E-T r-D P$

Eşitlikte; $\mathrm{Wr}_{\mathrm{t}}$ ve $\mathrm{Wr}_{\mathrm{t}+1}$ sırasıyla $\mathrm{t}$ ve $\mathrm{t}+1$ zamanda kök bölgesinde su içeriğini göstermektedir. Önemli yağışlardan veya aşırı sulamadan sonra, $\mathrm{Wr}$ tarla kapasitesini $\left(\mathrm{Wr}_{\mathrm{FC}}\right.$ ) aşarsa, derin sızma kayıpları (DP) meydana gelecektir.

$$
D P=W r_{F C}-W r
$$

Kök bölgesi tüketimi (Dr) ise $W r_{F C}$ seviyesi ile kök bölgesinde su eksilişi sonrasında oluşan toprak su düzeyi (Wr) arasındaki farkı ifade etmektedir.

$$
D r=W r_{F C}-W r
$$

\section{Sulama Yönetimi Verileri}

Sulama programları AquaCrop içerisinde kullanıcı tarafindan belirlenmiş zaman ve derinlik kriterleri yardımıyla planlanmaktadır (Raes, 2017). Derinlik kriteri olarak, Wr'yi tarla kapasitesi düzeyine ulaştırmak için gereksinim duyulan sulama suyu miktarı esas alınmıştır. Zaman kriteri olarak kullanıma hazır su miktarının (RAW) iki farklı yüzdesi kabul edilmiştir. Bu amaçla, \%100 RAW ve \%50 RAW tüketim düzeyleri sirasıly $\mathrm{S} 1$ ve S2 sulama seviyeleri olarak modelde incelenmiştir. Çalışmada başlangıç Wr düzeyinin tarla kapasitesinde olduğu kabul edilmiştir.

Net sulama suyu ihtiyacı belirlenirken, belirlenen kök bölgesi tüketim eşiği (p) aşıldığında sulama uygulaması gerçekleştirilmektedir. Kök bölgesinde izin verilen su tüketim eşiği kullanıma hazır toprak suyu (RAW) değerini belirlemektedir. Model tarafından RAW değerinin tarla kapasitesi ile stomaların kapanmaya başladığı tüketim seviyesi ( $p_{\text {sto. }}$ TAW) arasında yer aldığı varsayılmaktadır. Ayrıca stomal kapanma için toprak su tüketiminin üst eşiği $\left(\mathrm{p}_{\text {sto }}\right)$ TAW ile çarpıldığında kök bölgesi tüketiminin üst eşiği $\left(D_{\text {sto,upper }}\right)$ bulunmaktadır (Raes ve ark., 2012a). Modelde sabit (conservative) parametrelerden biri olarak varsayllan $p_{\text {sto }}$ patates bitkisi için 0.55 kabul edilmiştir (Raes ve ark., 2012b).

S2 sulama programı için modele aktarılan zaman kriteri S1 programından farklı olarak RAW değerinin \%50'si tüketildiğinde kök bölgesi toprak su içeriği tarla kapasitesine tamamlanacak şekilde ayarlanmıştır. Çalışmada optimum verime yönelik sulama planlaması yapılırken iklim, bitki, toprak ve sulama verileri dışındaki bileşenler modelin varsaydığı şekilde kabul edilmiştir. 


\section{Bulgular ve Tartışma}

\section{Referans Bitki Su Tüketimi}

ETo hesaplayıcı kullanılarak uzun yıllar aylık ortalama iklim verilerine göre hesaplanan her bir ay için günlük ortalama ETo değerleri Çizelge 4'de verilmiştir. En yüksek ETo değeri Temmuız ay1 için $5.9 \mathrm{~mm}_{\text {gün }}{ }^{-1}$ bulunurken, en düşük değer Aralık ayı için $1.0 \mathrm{~mm}_{\text {gün }}{ }^{-1}$ olarak hesaplanmıştır. Y1llı ortalama ETo değeri ise $1095.5 \mathrm{~mm}$ bulunmuştur.

Çizelge 4. ETo hesaplayıcı ile hesaplanmış referans bitki su tüketimi (ETo) değerleri

\begin{tabular}{lc}
\hline Aylar & ETo değerleri $\left(\mathbf{m m} \mathbf{~ g u ̈ n}^{-1}\right)$ \\
\hline Ocak & 1,1 \\
Şubat & 1,4 \\
Mart & 2,0 \\
Nisan & 2,9 \\
Mayis & 4,1 \\
Haziran & 5,4 \\
Temmuz & 5,9 \\
Ağustos & 5,2 \\
Eylül & 3,6 \\
Ekim & 2,0 \\
Kasim & 1,3 \\
Aralık & 1,0 \\
\hline
\end{tabular}

\section{Sulama Programları Simülasyon Sonuçları}

S1 sulama programı için simülasyon sonuçlarına göre patates bitkisi biyokütle ve kuru verim değerleri sırasıyla $12.636 \mathrm{t} \mathrm{ha}^{-1}$ ve $9.685 \mathrm{t} \mathrm{ha}^{-1}$ olarak bulunmuştur. Terleme (Tr), örtü yüzdesi gelişimi (CC) ve farklı renklerde stres eşik düzeylerini içeren (bitki örtüsü genişlemesi (Th1), stomal kapanma (Th2) ve erken olgunlaşma (Th3) stres eşikleri) kök bölgesi suyu tüketimi (Dr) simülasyonları Şekil 1'de gösterilmiştir. S1 sulama programı için kök bölgesi su tüketimine bağlı olarak patates bitkisi yetişme dönemi başlangıcında bitki örtüsü gelişiminin $\% 12$ oranında azaldığı Şekil 1'den görülmektedir. S1 sulama programı için topraktan buharlaşma $(\mathrm{E})$ ve bitkiden terleme (Tr) değerleri sırasıyla $108,4 \mathrm{~mm}$ ve $377,7 \mathrm{~mm}$ olarak tahmin edilmiştir. Sulama programı simülasyon sonuçları Çizelge 5'de sunulmuştur. S1 programında 7 sulama olayı gerçekleşmiş ve toplam net sulama suyu miktarı $340.7 \mathrm{~mm}$ olarak tahmin edilmiştir.

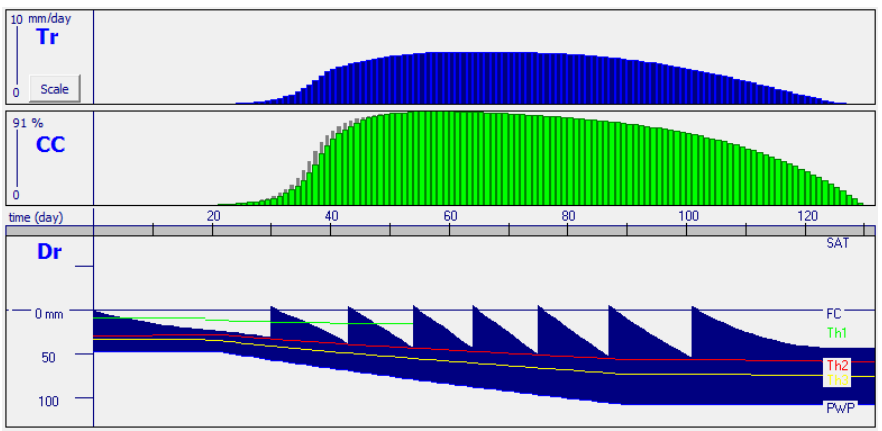

Şekil 1. S1 sulama programı bitki gelişimi simülasyonu

Çizelge 5. S1 sulama programı simülasyon sonucu

\begin{tabular}{ccc}
\hline Sulama sayısı & Sulama tarihleri & Net sulama suyu miktarı $(\mathbf{m m})$ \\
\hline 1 & 13 Mayis & 33,2 \\
2 & 26 Mayis & 42,1 \\
3 & 6 Haziran & 47,5 \\
4 & 16 Haziran & 47,9 \\
5 & 27 Haziran & 54,9 \\
6 & 9 Temmuz & 57,5 \\
7 & 23 Temmuz & 57.5 \\
\hline Toplam & & 340.7 \\
\hline
\end{tabular}


S2 sulama programı için tahmin edilen patates bitkisi biyokütle ve kuru verim değerleri sırasıyla $13.062 \mathrm{t} \mathrm{ha}^{-1}$ ve $9.535 \mathrm{t} \mathrm{ha}^{-1}$ olmuş ve Tr, CC ve Dr simülasyonları Şekil 2'de gösterilmiştir. S2 için buharlaşma (E) ve terleme (Tr) değerleri sırasılyla $126.9 \mathrm{~mm}$ ve $387.7 \mathrm{~mm}$ olarak tahmin edilmiştir. Çizelge 6'dan görüleceği üzere S2 programında model 17 sulama olay1 gerçekleştirmiştir. Modelde toplam net sulama suyu miktarı $401.5 \mathrm{~mm}$ olarak tahmin edilmiştir.

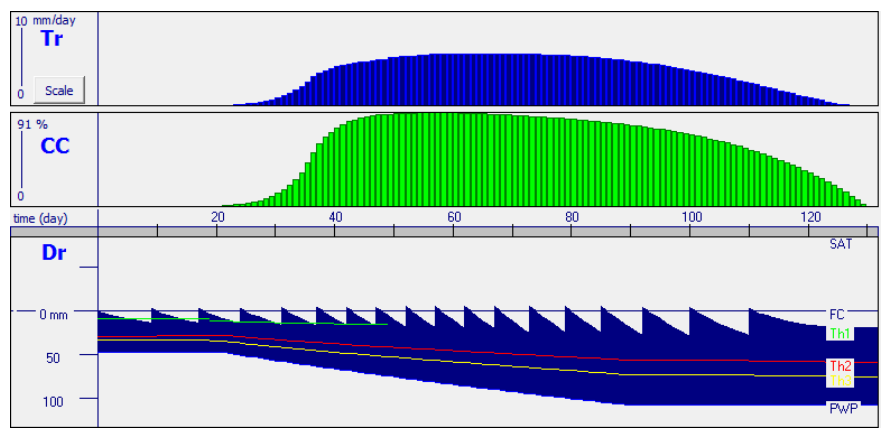

Şekil 2. S2 sulama programı bitki gelişimi simülasyonu

Çizelge 6. S2 sulama programı simülasyon sonucu

\begin{tabular}{ccc}
\hline Sulama sayısı & Sulama tarihleri & Net sulama suyu miktari $(\mathbf{m m})$ \\
\hline 1 & 22 Nisan & 15,2 \\
2 & 30 Nisan & 15,0 \\
3 & 7 Mayis & 16,0 \\
4 & 14 Mayis & 18,3 \\
5 & 20 Mayis & 20,3 \\
6 & 25 Mayis & 20,1 \\
7 & 30 Mayis & 21,3 \\
8 & 4 Haziran & 22,1 \\
9 & 9 Haziran & 23,1 \\
10 & 14 Haziran & 24,2 \\
11 & 19 Haziran & 24,6 \\
12 & 25 Haziran & 30,1 \\
13 & 1 Temmuz & 28,9 \\
14 & 7 Temmuz & 28,9 \\
15 & 14 Temmuz & 31,6 \\
16 & 22 Temmuz & 31,7 \\
17 & 1 Ağustos & 30,0 \\
\hline Toplam & & 401,5 \\
\hline
\end{tabular}

AquaCrop modeli kuru verim değerini tahmin etmektedir. Bu nedenle, model hesaplamaları sonucu elde edilen kuru verim miktarları, yapılmış çalışmalar ile karşılaştırılırken, kaynak araştırmalarından elde edilen patates yumru verimi değerleri, yumru kuru madde oranı ile çarpılmıştır. Patates yumrusunda kuru madde oranı, nişasta oranı ile doğru orantılı bir kalite kriteridir (Schippers, 1976). Patates yumrularında kuru madde oranı \% 17 ile \% 22 arasında değişmektedir (Esendal, 1990).

Her iki sulama programında da model tarafindan tahmin edilen kuru verim değerleri birbirine yakınlık göstermiş̧tir. Ayas (2007) tarafından patates bitkisinde dönemsel kısıntılı sulamanın verim ve kalite özellikleri üzerine etkilerini belirlemek amacıyla yürütülen çalışmada, tam sulama konusunda patates yumru verimi ortalama olarak $5000 \mathrm{~kg} \mathrm{da}^{-1}$ bulunmuştur. Yaklaşık kuru verim, \% $20 \mathrm{kuru}$ madde oranına göre $10 \mathrm{t} \mathrm{ha}^{-1}$ olarak hesaplanmıştır. Mazurczyk ve ark. (2009) tarafından yapılan çalışmada patates kuru verimi $11 \mathrm{t} \mathrm{ha}^{-1}$ olarak bulunmuştur. Bu çalışmalarda elde edilen sonuçlar, AquaCrop modeli ile tahmin edilen sonuçlarla paralellik göstermiştir.

S1 ve S2 sulama programları arasındaki $60.8 \mathrm{~mm}$ net sulama suyu miktarı farkının, temelde model tarafından simüle edilen sulama olayı sayıları arasındaki farklılıktan kaynaklandığı söylenilebilir. S1 ve S2 programları için model tarafından tahmin edilen ET değerleri sırasıyla 485.8 mm ve $513.7 \mathrm{~mm}$ olmuştur. Yavuz (2011) tarafindan Konya Ovasında yürütülen çalışmada patates bitkisi için mevsimlik bitki su tüketimi $572.17 \mathrm{~mm}$ bulunmuştur. Doorenbos ve Kassam (1979), 
patates su tüketiminin, iklim ve bitki koşullarına bağlı olarak 500-700 mm arasında değişebileceğini belirtmişlerdir. AquaCrop modeli ile sulama programlarına göre tahmin edilen ET değerleri yukarıdaki çalışmalarda elde edilen ET değerlerine yakınlık göstermiştir.

\section{Sonuç ve Öneriler}

AquCrop 5.0 modeli simülasyon sonuçlarına göre, patates bitkisi için suyun tasarruflu kullanımı bakımından S1 sulama programı (zaman kriteri \%100 RAW tüketim düzeyi) öne çıkmıştır. $\mathrm{Bu}$ sulama programında model tarafindan tahmin edilen patates bitkisi ET, biyokütle ve kuru verim değerleri sırasıyla $485.8 \mathrm{~mm}, 12.636 \mathrm{t} \mathrm{ha}^{-1}$ ve $9.685 \mathrm{t} \mathrm{ha}^{-1}$ olmuştur. S1 sulama programının, çalışmada öngörülen iklim, toprak ve bitki koşullarında patates bitkisi için uygulanabileceği söylenilebilir. Fakat, ileri aşamada yürütülecek bir arazi çalışması girdilerinin modele aktarılarak, arazi çalışması sonuçlarıyla, simülasyon sonuçlarının karşılaştırılması ve modelin test edilmesi önerilmektedir.

Not: Bu çalışma, Derya BEYHAN YİĞIT’in Yüksek Lisans tezinden özetlenmiştir.

\section{Teşekkür}

Sorularımı ilgi ile yanıtlayan Bursa Uludağ Üniversitesi Ziraat Fakültesi Tarla Bitkileri Bölümü’nden Prof. Dr. Mehmet SINCCIK ve Leuven Üniversitesi Biyobilim Mühendisliği Fakültesi Yer ve Çevre Bilimleri Bölümü’nden Prof. Dr. Dirk RAES ile Araştırma Görevlisi Hanne Van GAELEN'a teşekkürlerimi sunarım.

\section{Kaynaklar}

Araya, A., Haptu, S., Hadgu, K.M., Kebede, A., Dejene, T., 2010. Test of AquaCrop model in simulating biomass and yield of water deficient and irrigated barley (Hordeum vulgare). Agricultural Water Management. 97(11): 1838-1846.

Arıŏlu, H., Çalışkan, M.E., Onaran, H., 2006. Türkiye'de patates üretimi, sorunları ve çözüm önerileri. IV. Ulusal Patates Kongresi, 06-08 Eylül 2006, Bildiler Kitabı, s: 1-10, Niğde.

Ayas, S., 2007. Kısıntılı Sulanan Patatesin Su-Verim İlişkisi. U.Ü. Fen Bil. Ens., Tarımsal Yapılar ve Sulama ABD, Doktora Tezi, $241 \mathrm{s.}$

Belmans, C., Wesseling, J.G., Feddes, R.A., 1983. Simulation model of the water balance of cropped soil: SWATRE. Journal of Hydrology. 63(3-4): 271-286.

Doorenbos, J., Kassam, A.H., 1979. Yield Response to Water. Irrigation and Drainage Paper No: 33, FAO Rome, Italy, $193 \mathrm{pp}$.

Esendal, E., 1990. Nişasta Şeker Bitkileri ve Islahı Cilt: 1 Patates, Ondokuz Mayıs Üniversitesi, Ziraat Fakültesi, No: 49, Samsun, $221 \mathrm{~s}$.

FAO, 2015. Food and Agriculture Organization of the United Nations, AquaCrop new features and updates Version 5.0, http://www.fao.org/nr/water/aquacrop.html

Farahani, H.J., Izzi, G., Oweis, T.Y., 2009. Parameterization and evaluation of the AquaCrop model for full and deficit irrigated cotton. Agronomy Journal. 101(3): 469-476.

García-Vila, M., Fereres, E., Mateos, L., Orgaz, F., Steduto, P., 2009. Deficit irrigation optimization of cotton with AquaCrop. Agronomy Journal. 101(3): 477-487.

Geerts, S., Raes, D., Garcia, M., Miranda, R., Cusicanqui, J.A., Taboada, C., Mendoza, J., Huanca, R., Mamani, A., Condori, O., Mamani, J., Morales, B., Osco, V., Steduto, P., 2009. Simulating Yield Response of Quinoa to Water Availability with AquaCrop. Agronomy Journal. 101(3): 499-508.

GTHB-BUGEM, 2016. T.C. Gıda Tarım ve Hayvancılık Bakanlığı Bitkisel Üretim Genel Müdürlüğü Bitkisel Üretim Verileri, Erişim: Nisan 2016 www.tarim.gov.tr/sgb/Belgeler/SagMenuVeriler/BUGEM.pdf

Hsiao, T.C., Heng, L., Steduto, P., Rojas-Lara, B., Raes, D., Fereres, E., 2009. AquaCrop-The FAO crop model to simulate yield response to water: III. Parameterization and testing for maize. Agronomy Journal. 101(3): 448-459.

Jensen, M.E., 1980. Design and Operation of Farm Irrigation Systems. An ASAE monograph Number 3. American Society of Agricultural Engineers, 2950 Niles Road, Michigan 49085, USA, p. 829.

Kale, S., Tarı, A.F., 2012. Sulu ve Kuru Koşullar Altında Kışlık Buğday İçin FAO-AquaCrop Modelinin Performansının değerlendirilmesi. Toprak Su Dergisi. 1(2): 119-131.

Kashyap, P.S., Panda, R.K., 2003. Effect of irrigation scheduling on potato crop parameters under water stressed conditions. Agricultural Water Management. 59(1): 49-66.

Mazurczyk, W., Wierzbicka, A., Trawczyński, C., 2009. Harvest index of potato crop grown under different nitrogen and water supply. Acta Scientiarum Polonorum series Agricultura. 8(4): 15-21.

MGM, 2013. Bursa Merkez Meteoroloji İstasyonu, T.C. Orman ve Su İşleri Bakanlığı, Meteoroloji Genel Müdürlüğ̈̈, Ankara, 1970-2012. 
doi:10.33202/comuagri.519649

MGM, 2018. T.C. Orman ve Su İşleri Bakanlığı, Meteoroloji Genel Müdürlüğü, İklim Sınıflandırmaları, Erişim: 26.02.2018, https://www.mgm.gov.tr/iklim/iklim-siniflandirmalari.aspx?m=BURSA

Raes, D., Steduto, P., Hsiao, T.C., Fereres, E., 2009. AquaCrop - The FAO Crop Model to Simulate Yield Response to Water: II. Main Algorithms and Software Description. Agronomy Journal. 101(3): 438-447.

Raes, D., Steduto, P., Hsiao, T.C., Fereres, E., 2011. FAO Crop Water Productivity Model to Simulate Yield Response to Water. Reference Manual, Chapter 1 - AquaCrop, Version 3.1 plus, January 2011, Erişim: Mart 2015, http://www.fao.org/nr/water/docs/AquaCropV31plusChapter1.pdf

Raes D 2012. The ETo Calculator, Reference Manual (Version 3.2, September 2012), Food and Agriculture Organization of the United Nations, Land and Water Division, Rome, Italy http://www.fao.org/landwater/databases-and-software/eto-calculator/en/.

Raes, D., Steduto, P., Hsiao, T.C., Fereres E 2012a. Calculation procedures, Reference Manuel, Chapter 3AquaCrop Version 4.0, June 2012, Erişim: Mart 2015, http://www.fao.org/nr/water/docs/AquaCropV40Chapter3.pdf

Raes, D., Steduto, P., Hsiao, T.C., Fereres, E., 2012b. Reference Manuel, Annex I, AquaCrop Version 4.0, June 2012, Erişim: Mayıs 2015, http://www.fao.org/nr/water/docs/AquaCropV40Annexes.pdf

Raes, D., 2017. AquaCrop Training Handbooks, Book I. Understanding AquaCrop, Food and Agriculture Organization of the United Nations, Rome, Italy, http://www.fao.org/3/a-i6051e.pdf

Ritchie, J.T., 1972. Model for predicting evaporation from a row crop with incomplete cover. Water Resources Research. 8(5): 1204-1213.

Ritchie, J.T., Godwin, D.C., Otter-Nacke, S., 1985. CERES-Wheat. A Simulation Model of Wheat Growth and Development. Texas A. \& M Univ. press, College station.

Steduto, P., Hsiao, T.C., Raes, D., Fereres, E., 2009. AquaCrop - The FAO crop model to simulate yield response to water: I. Concepts and underlying principles. Agronomy Journal. 101(3): 426-437.

Harper, P., 1963. Optimum Leaf Area Index in the potato Crop. Nature. 197: 917-918

Schippers, P.A., 1976. The Relationship Between Specific Gravity and Persentage Dry Matter in Potato Tubers. American Potato Journal. 53(4): 111-122.

Todorovic, M., Albrizio, R., Zivotic, L., Abi Saab, M., Stöckle, C., Steduto, P., 2009. Assessment of AquaCrop, CropSyst, and WOFOST models in the simulation of sunflower growth under different water regimes. Agronomy Journal. 101(3): 509-521

Yazgan, S., Tatar, D., 2003. Bitki Gelişiminin Benzetimi (Simülasyonu) (Ceres-Wheat Modeli). Atatürk Üniversitesi Ziraat Fakültesi Dergisi. 34(2): 161-166.

Yavuz, D., 2011. Patates Tarımında Farklı Sulama Yöntemlerinin Su Kullanımı, Verim ve Enerji Tüketimi Yönünden Karşılaştırılması. S.Ü. Fen Bil. Ens., Tarımsal Yapılar ve Sulama ABD, Doktora Tezi, 129 s.

Zeleke, K.T., Luckett, D., Cowley, R., 2011. Calibration and testing of the FAO AquaCrop model for canola. Agronomy Journal. 103(6): 1610-1618. 